\title{
Statistical Process Control of Surface Roughness DURING CO2 LASER CUTTING USING OXYGEN AS ASSIST GAS
}

\author{
Derzija Begic-Hajdarevic, Mugdim Pasic, Branko Vucijak, Ahmet Cekic \\ Faculty of Mechanical Engineering, University of Sarajevo, Vilsonovo setaliste 9, Sarajevo 71000, Bosnia and \\ Herzegovina
}

\begin{abstract}
The surface roughness of the end product is a very important indicator of laser cutting quality. The paper reports a comparison of surface roughness during $\mathrm{CO} 2$ laser cutting of tungsten alloy plate using oxygen as assist gas, based on control charts made by statistical process control (SPC) approach. Dependent variable is surface roughness, while independent variables are laser power and cutting speed. The control chart used within this paper is a variation of the ichart of experimental data samples, where using evaluation of moving range of the two consecutive values, in order to estimate value of standard error by average moving range and Hartley's constant d2. Applying the criteria often used in the SPC methods for the assessment of "out of control" situations, it may be inferred that the observed differences in surface roughness during $\mathrm{CO} 2$ laser cutting could be used to advice on the more appropriate laser power and cutting speed for the laser cutting quality.
\end{abstract}

Keyword: laser cutting process; statistical process control; control chart; surface roughness; tungsten alloy
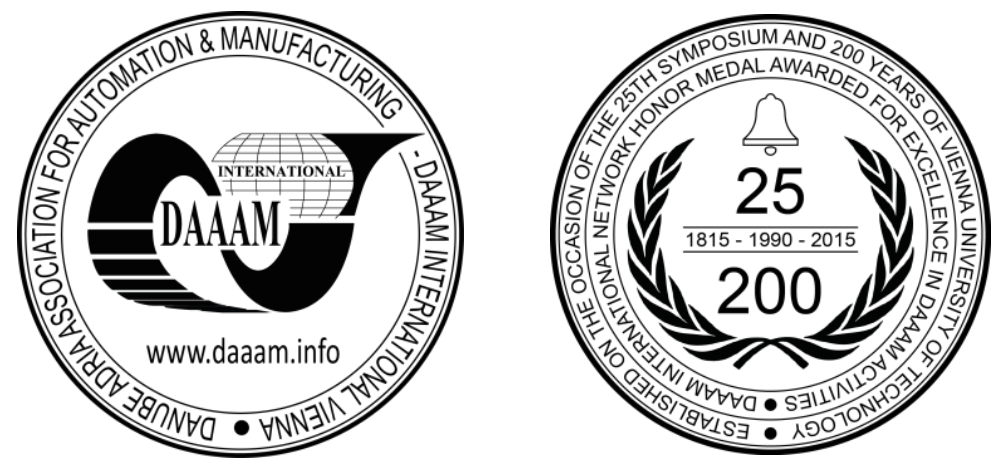

This Publication has to be referred as: Begic-Hajdarevic, D[erzija]; Pasic, M[ugdim]; Vucijak, B[ranko] \& Cekic, A[hmet] (2016). Statistical Process Control of Surface Roughness during CO2 Laser Cutting using Oxygen as Assist Gas, Proceedings of the 26th DAAAM International Symposium, pp.0247-0255, B. Katalinic (Ed.), Published by DAAAM International, ISBN 978-3-902734-07-5, ISSN 1726-9679, Vienna, Austria DOI:10.2507/26th.daaam.proceedings.034 


\section{Introduction}

Modern nonconventional machining methods are established to fabricate difficult-to-machine materials such as high-strength thermal-resistant alloys; various kinds of carbides, fiber-reinforced composite materials, ceramics and so on. Conventional machining process of such materials produces high cutting forces that, in some particular cases, may not be sustained by the workpiece. Laser beam machining (LBM) offers a good solution that is indeed more associated with material properties such as thermal conductivity and specific heat as well as melting and boiling temperatures. Laser beam machining is a flexible process. When combined with a multi-axis workpiece positioning system, the laser beam can be used for drilling, cutting, grooving, welding and heat treating processes on a single machine [1]. There are various aspects of laser beam machining that can be modeled with different methods in order to predict quality characteristics which are essential for any manufacturing process [2]. In [3] is developed a technique to predict surface roughness in the laser cutting process for the first time by analysing the dynamic phenomenon that happens within the cutting front. The quality characteristics (such as kerf width, surface roughness and cut edge slope) were observed for the various of cutting parameters such as laser power, cutting speed and assist gas pressure during pulsed $\mathrm{CO}_{2}$ laser cutting of $\mathrm{Al} 6061 / \mathrm{SiCp} / \mathrm{Al}_{2} \mathrm{O}_{3}$ composite [4]. Authors used a hybrid approach of grey based response surface methodology for predicting the optimal combination of laser cutting parameters. A grey relational analysis was used to determine a single optimized set of cutting parameters in precision laser cutting of three different thermoplastics [5]. It was found that the laser power has dominant effect on heat affected zone for all thermoplastics. For further analysis are interesting especially uncommon materials and alloys where the common knowledge is not applicable [6]. The effect different process parameters such as laser power, cutting speed and oxygen assist gas pressure on the cutting quality during $\mathrm{CO}_{2}$ laser cutting of tungsten alloy was analyzed in [7]. It was found that oxygen assist gas pressure has strong influence on the cut quality.

In laser cutting process, many factors affecting the end product quality. Some of these factors include the cutting speed and the laser power. The paper reports a comparison of surface roughness in $\mathrm{CO}_{2}$ laser cutting of tungsten alloy plate using oxygen as assist gas, based on control charts made by statistical process control (SPC) approach.

\subsection{Use of statistical process control}

Vilfredo Pareto (1848-1923), who was trained as an engineer but is best known for his economic and sociological works, has set one of the basic optimization postulates of statistical process control (SPC). He noticed that many failures in a system are resulting from small number of causes and that in production process rarely some "general malaise" is causing problems. Pareto found that even though some companies show both diligence and hard work, and even strong motivation in some cases, still the quality of the product or service was poor. Thus in order to improve such system, for production, management or providing services, it is required to find and correct those causes, also called "Pareto glitches" [8].

During 1920s Walter Shewhart developed the basic theory of statistical process control [9], which was widely popularized at the later time by Edwards Deming [8]. They noticed that the repeated measurements of a single process will show some level of variation. If the process is stable, its variation will be predictable and it is possible to describe it with statistical distributions, among which normal distribution is most frequently used. Even though Shewhart originally started working with manufacturing processes, both he and Deming understood that such observation could be applied to any sort of process.

Statistical process control methods provide objective means of controlling the quality in any transformation process. W.E. Deming wrote that quality and productivity increase as variability decreases and, because variations are unavoidable, statistical methods of quality control must be used to measure and gain understanding of the causes of the variation. Application of the statistical process control concept aims enabling steady improvement in the quality of a product, even while dealing with the everyday crises which are unavoidable part of any production or service process. It needs to be underlined that the statistical process control is completely different from the end product inspection conveniently associated with "quality assurance". It is generally consisting of three phases as follows:

- Provision of a flowchart of the process, clearly separating process functions and steps;

- Random sampling and measuring, usually at regular temporal intervals, at different phases/functions of the process;

- Provision of "control chart(s)" aiming to recognize such "Pareto glitches", all in order to discover and remove their causes.

It is considered that the inherent nature of any process has some common cause variations that are not possible to be altered, without changing the process itself. But 'assignable' or 'special' causes of variation are unusual disruptions to the process, the causes of which can and should be removed, of course after being recognized as such. One key purpose of SPC is to distinguish between these two types of variation, aiming to avoid both over-reaction and under-reaction or lack of needed response to the process. It assists in recognizing situations where reaction relates to the cause that has sufficient impact, and which is practical and economic to remove it in order to improve the quality [10].

Essence of statistical process control is to differentiate causes of process variation. Some variations belong to the category of chance or random variations, considered as inherent to the process and they could be removed only with 
revising the whole process. But other causes of variation, relatively large in magnitude and possible to be identified, are conveniently classified as 'assignable' or 'special' causes. When special causes of variation are present, variation is excessive and the process is classified as 'unstable' or 'out of statistical control'.

Thus SPC tries to respond to the two key questions, which are: (1) "Is the process in-control", and (2) "What is the extent of the process variability". A response to these questions actually relates to potential presence of any special causes of variation, or is the variability due only to the natural process capability, what entails that only common causes of variation are present.

To control a process using data, one needs to monitor the current state of the accuracy and precision of the distribution of the data what is typically done using control charts. A control chart can be conveniently compared with a traffic signal - green light is given when the process is running properly and does not need any adjustments (process is under control), meaning that only common causes of variation are present. Next level is amber light, which signals that some discrepancy to the natural process might be present. Red light clearly shows that assignable or special cause(s) of variation appeared before the occurrence of such data and the process is definitely out of control. But such control mechanism may be used only when the process itself is "in statistical control", meaning that it did not change its main behavior characteristics, such as the mean or the variance. It was foreseen that such an approach would be primarily used in production processes.

The SPC methods are used today for different problems like healthcare [11], software processes [12], statistical inference at work [13], even climate change assessments [14, 15] and others; however, its use for evaluation of cutting processes is still limited.

\section{Experimental setup}

The experiments were carried out on a Rofin $\mathrm{CO}_{2}$ laser system (model DC020) with a nominal output power of $2000 \mathrm{~W}$ in $\mathrm{CW}$ mode at a wavelength of $10.6 \mu \mathrm{m}$ with a high quality beam (beam quality factor $K=0.95$ ). The experimental investigations were conducted at the University of Applied Science Jena in Germany. Tungsten alloy ( $W \approx$ $92,5 \%$ and rest $\mathrm{Fe}$ and $\mathrm{Ni}$ ) sheet with thickness of $1 \mathrm{~mm}$ was used for experimentation. The products manufactured of the tungsten alloy sheets find new possibilities for the application in different industrial areas, e.g. in medical application, the automobile sectors and aircraft industry. The laser beam was focused using a $127 \mathrm{~mm}$ focal length lens. Oxygen assist gas was used coaxially with the laser beam via a $2 \mathrm{~mm}$ exit diameter nozzle. Two input process parameters have been selected for the present study. These are laser power and cutting speed. The range of process parameters utilized is summarized in table 1. Testing the effect of one parameter on the cut quality requires the variation of one parameter while keeping the other parameters at the pre-selected values.

\begin{tabular}{cccccc}
\hline Laser Power & Cutting Speed & Assist Gas Type & Assist Gas Pressure & Focus Position & Stand-off \\
\hline $1500-2000 \mathrm{~W}$ & $3000-6000 \mathrm{~mm} / \mathrm{min}$ & Oxygen & $12,5 \mathrm{bar}$ & $-0,5 \mathrm{~mm}$ & $1 \mathrm{~mm}$ \\
\hline
\end{tabular}

Table 1. Input process parameters and their values used in experiments

The controlled parameter was the surface roughness. A visual inspection of each cut was carried out to ensure that no pitting and burrs are present in the cut area. Surface roughness on the cut edge was measured in terms of the average roughness $R_{a}(\mu \mathrm{m})$, using a Taylor-Hobson stylus instrument. Roughness was measured at 20 different places along the length of cut at approximately in the middle of thickness.

Limitations of the research were primarily related to the limited number of samples. Response to this limitation was to use specific control charts, conveniently used for small number of measurements

\section{SPC i-charts for laser cutting data}

The simplest variable chart which may be used is one for individual measurements, the so-called " $i$-chart". The $i$-chart is simple and indicates changes in the mean level. With careful attention, the $i$-chart will even indicate changes in variability; however, it is not so good at detecting small changes in process centring [16].

The control chart used within this paper is a variation of the $i$-chart of data samples, where using evaluation of moving range of the two consecutive values, in order to estimate value of standard error using average moving range and Hartley's constant $\mathrm{d}_{2}$. The centreline (CL) is placed at the mean of the past performance, the action lines (upper and lower, UAL and LAL) are placed at three standard errors (SE) from the centreline. The warning lines (upper and lower, UWL and LWL) are placed at two standard errors from the sample means. If the process is stable, it may be expected that most of the individual values lie within the range $X \pm 3$ SE [16], based on the assumption of the normal data distribution.

When plotting the individual results on the $i$-chart, the rules for "out of control" situations are the following:

- $\quad$ any points falling outside the 3 SE limits;

- two out of three successive points are outside the 2 SE limits;

- $\quad$ eight points in a run on one side of the mean. 
Due to relative insensitivity of the $i$-charts, horizontal lines at $\pm 1 \mathrm{SE}$ on either side of the mean may be presented as well. It might be considered that the process is out of control if four of five points plot outside these limits, but this situation will not be addressed here. This research is based on experimental data in $\mathrm{CO}_{2}$ laser cutting of tungsten alloy by using different laser power and cutting speed such as: laser power of $2000 \mathrm{~W}$ and cutting speed of 3000, 3500, 4000, $4500,5000,5500$ and $6000 \mathrm{~mm} / \mathrm{min}$, laser power of $1750 \mathrm{~W}$ and cutting speed of 3000, 3500, 4000, 4500, 5000 and $5500 \mathrm{~mm} / \mathrm{min}$, so as laser power of $1500 \mathrm{~W}$ and cutting speed of 3000, 3500, 4000 and $4500 \mathrm{~mm} / \mathrm{min}$. For each of the above listed 17 different cases 20 cuttings were made and related surface roughness was measured, resulting sequences of 20 measures were used to create control $i$-charts. Results are presented with the following charts.

The below figure 1 relates to $i$-chart for laser power of $1500 \mathrm{~W}$ and cutting speed of $3000 \mathrm{~mm} / \mathrm{min}$. It can be seen that there are no points of the chart outside of area between the warning lines, meaning that the process is under control.

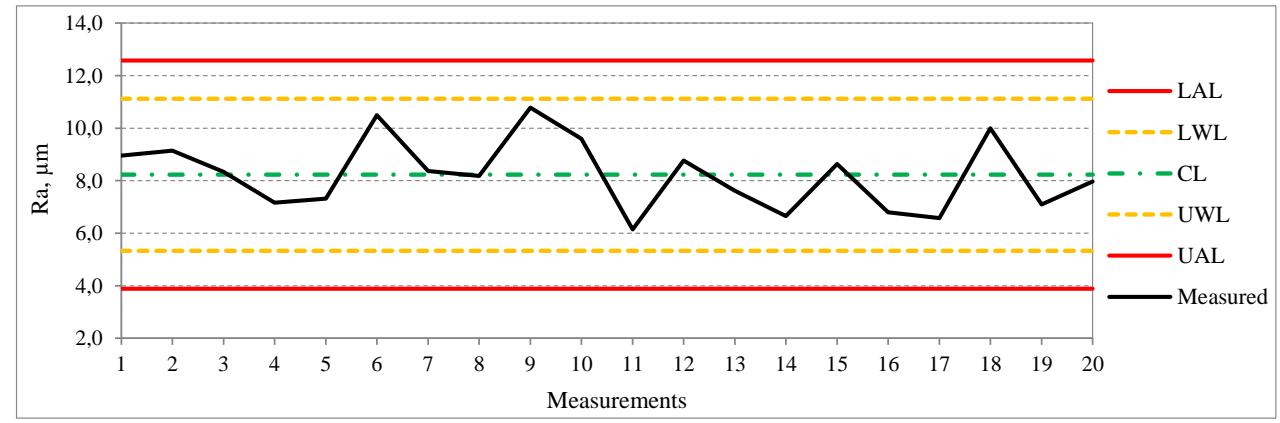

Fig. 1. $i$-chart for laser power of $1500 \mathrm{~W}$ and cutting speed of $3000 \mathrm{~mm} / \mathrm{min}$

Figure 2 shows that there is only one point of the chart above the upper warning line (point 7), what can be considered as statistically expected and the process is under control.

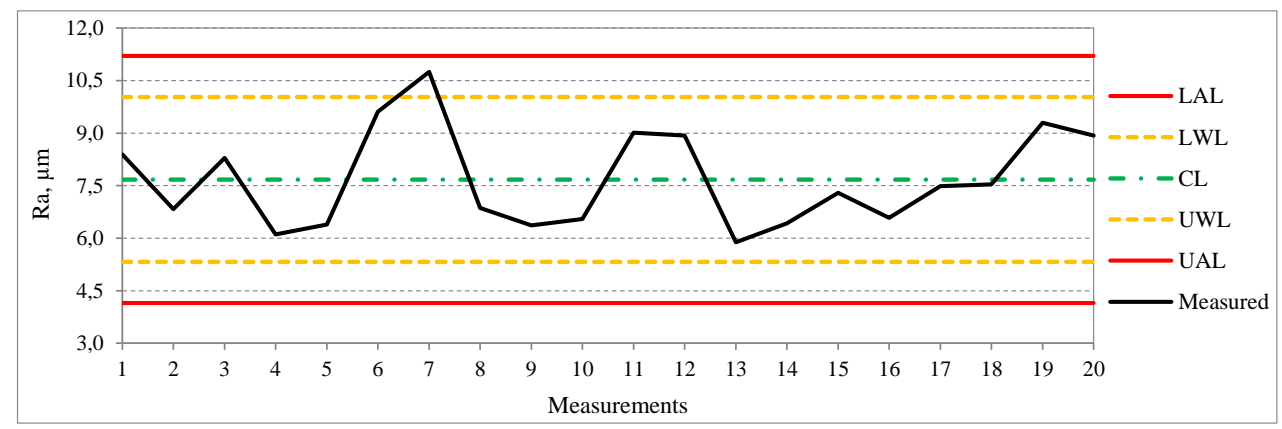

Fig. 2. $i$-chart for laser power of $1500 \mathrm{~W}$ and cutting speed of $3500 \mathrm{~mm} / \mathrm{min}$

Figure 3 depicts that there are no points of the chart outside of area between the warning lines, meaning that the process is under control, but the figure 4 shows that there two points of the chart above the upper warning line (points 12 and 15), what cannot be considered as statistically expected with this size of a sample (it may be expected that about 1 of 40 points is outside of these limits) and the process is not fully under control.

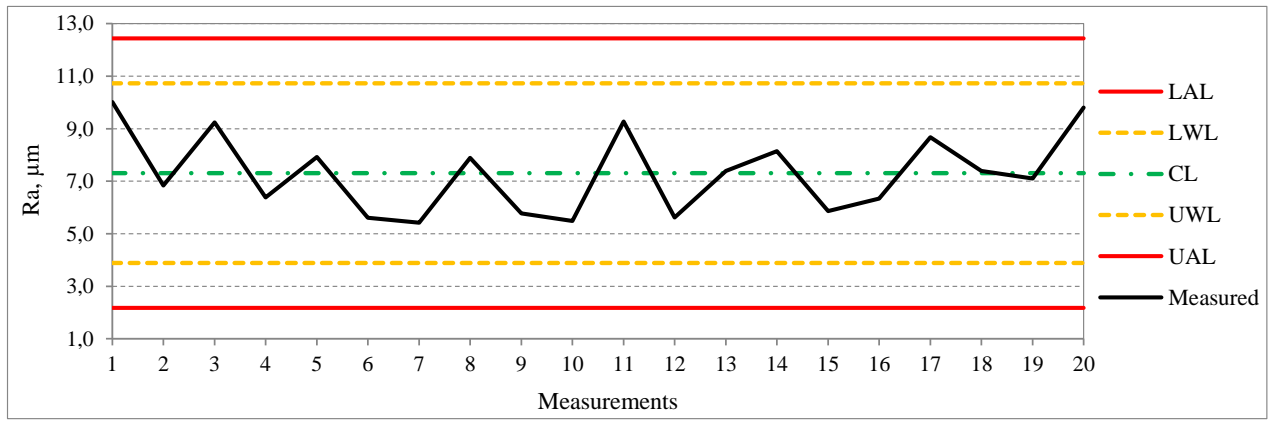

Fig. 3. $i$-chart for laser power of $1500 \mathrm{~W}$ and cutting speed of $4000 \mathrm{~mm} / \mathrm{min}$ 


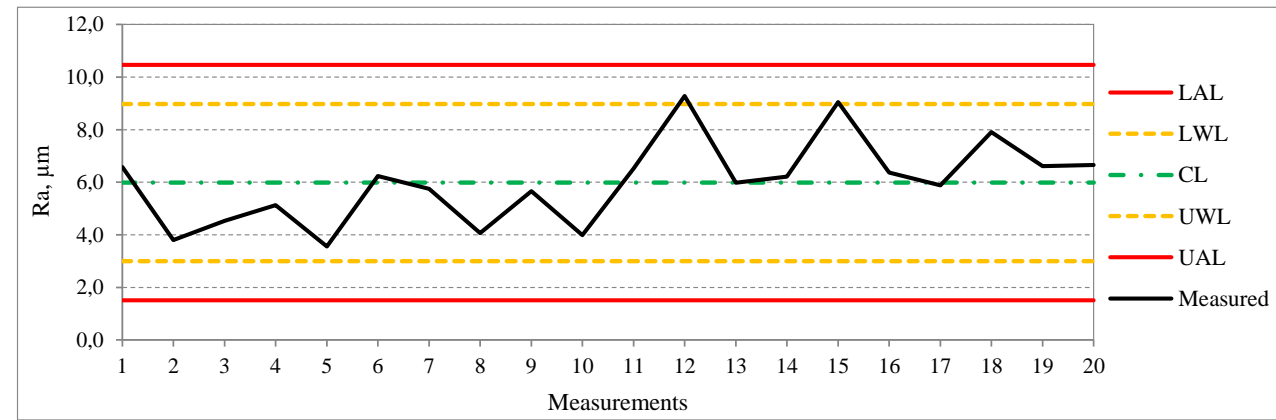

Fig. 4. $i$-chart for laser power of $1500 \mathrm{~W}$ and cutting speed of $4500 \mathrm{~mm} / \mathrm{min}$

The below figure 5 relates to $i$-chart for laser power of $1750 \mathrm{~W}$ and cutting speed of $3000 \mathrm{~mm} / \mathrm{min}$. The only point of the chart above the upper warning line is point 9 , what can be considered as statistically expected.

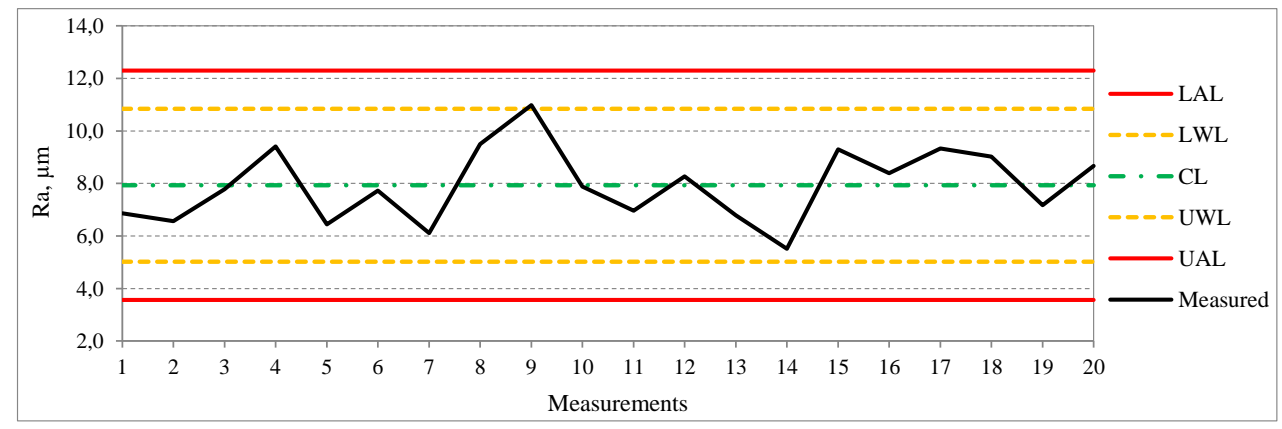

Fig. 5. $i$-chart for laser power of $1750 \mathrm{~W}$ and cutting speed of $3000 \mathrm{~mm} / \mathrm{min}$

Figures 6, 7 and 8 present that there are no points of the chart outside of area between warning lines, meaning that the process is under control, but the figure 9 presents that there are even four points of the chart above the upper warning line (points 6 and consecutive points 15-17), so as one point of the chart below the lower warning line (point 8), what means that the process is not under control.

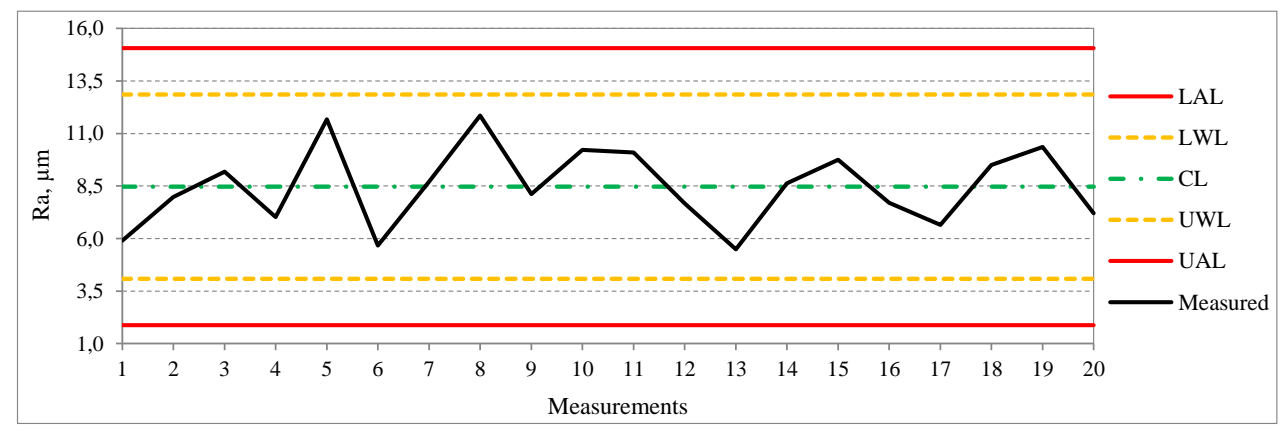

Fig. 6. $i$-chart for laser power of $1750 \mathrm{~W}$ and cutting speed of $3500 \mathrm{~mm} / \mathrm{min}$

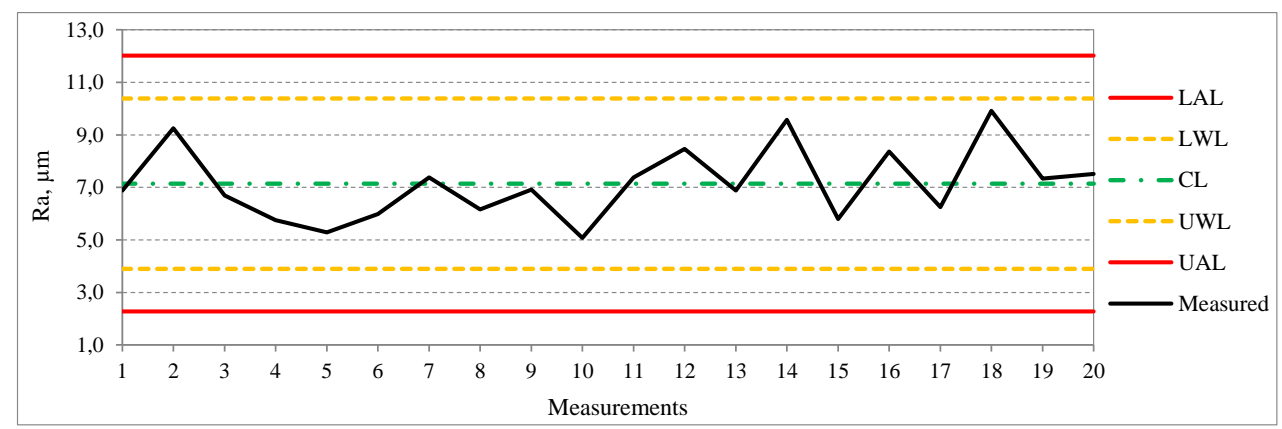

Fig. 7. $i$-chart for laser power of $1750 \mathrm{~W}$ and cutting speed of $4000 \mathrm{~mm} / \mathrm{min}$ 


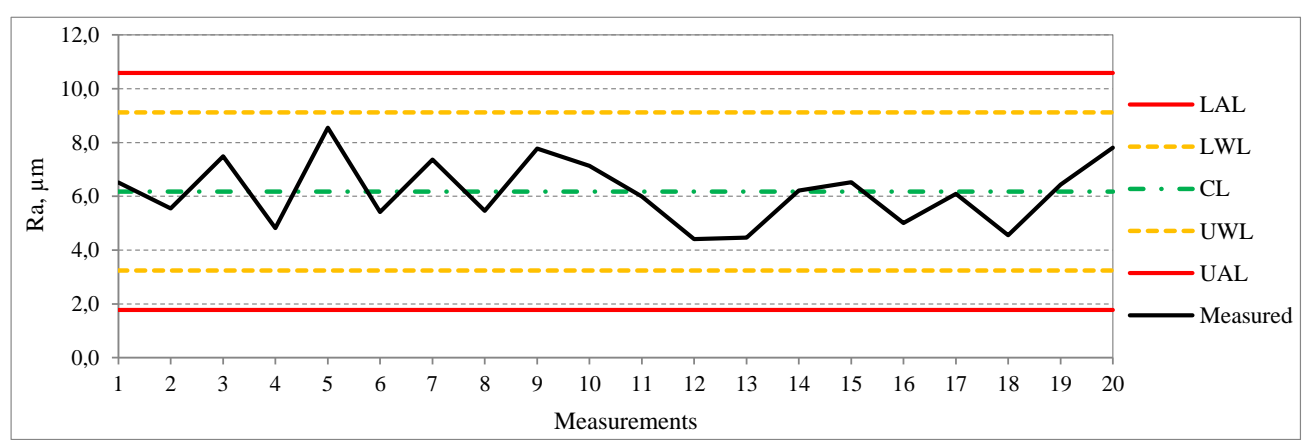

Fig. 8. $i$-chart for laser power of $1750 \mathrm{~W}$ and cutting speed of $4500 \mathrm{~mm} / \mathrm{min}$

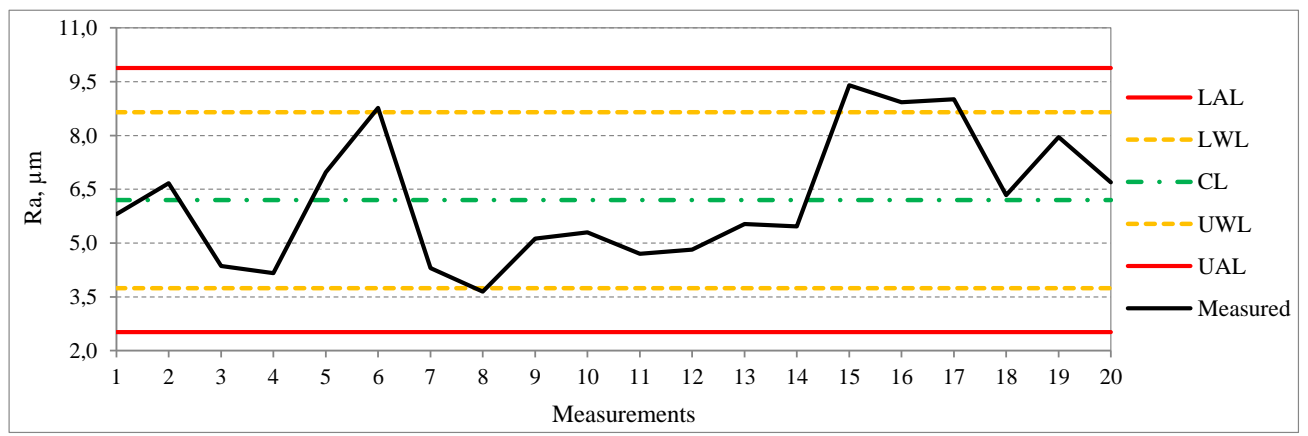

Fig. 9. $i$-chart for laser power of $1750 \mathrm{~W}$ and cutting speed of $5000 \mathrm{~mm} / \mathrm{min}$

The below figure 10 relates to $i$-chart for laser power of $1750 \mathrm{~W}$ and cutting speed of $5500 \mathrm{~mm} / \mathrm{min}$. It can be seen that there is only one point of the chart above the upper warning line (point 15), what can be considered as statistically expected and the process is under control.

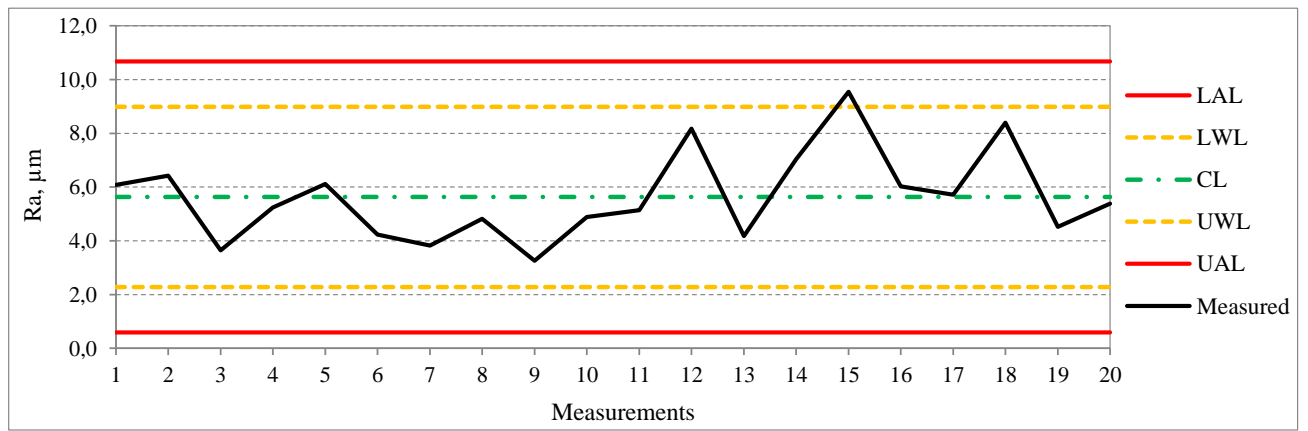

Fig. 10. $i$-chart for laser power of $1750 \mathrm{~W}$ and cutting speed of $5500 \mathrm{~mm} / \mathrm{min}$

The below figure 11 relates to $i$-chart for laser power of $2000 \mathrm{~W}$ and cutting speed of $3000 \mathrm{~mm} / \mathrm{min}$. It can be seen that there is only one point of the chart below the lower warning line (point 17), what can be considered as statistically expected and the process is under control.

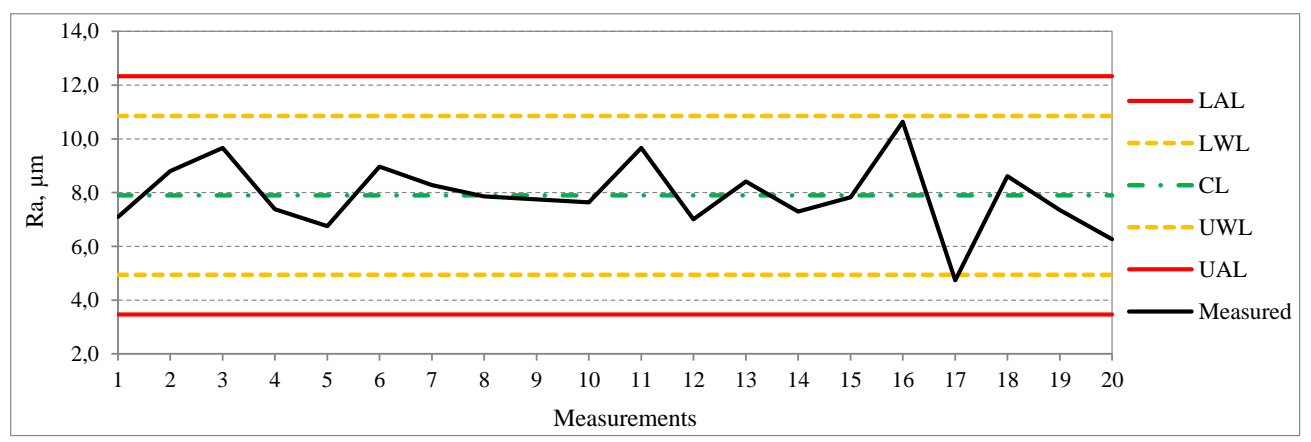

Fig. 11. $i$-chart for laser power of $2000 \mathrm{~W}$ and cutting speed of $3000 \mathrm{~mm} / \mathrm{min}$ 
Figures 12,13 and 14 relate to $i$-chart with no points outside of area between warning lines, meaning that the process is under control.

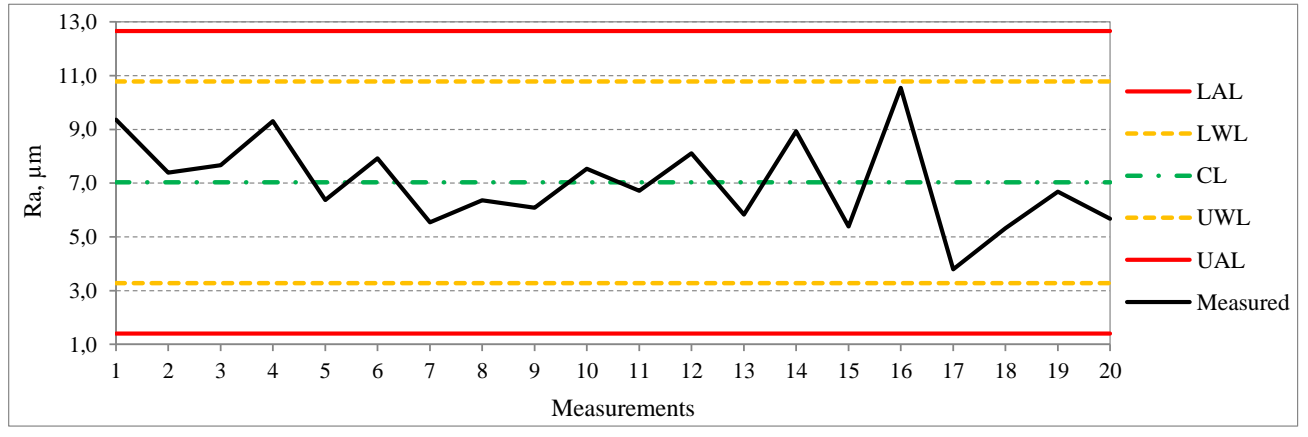

Fig. 12. $i$-chart for laser power of $2000 \mathrm{~W}$ and cutting speed of $3500 \mathrm{~mm} / \mathrm{min}$

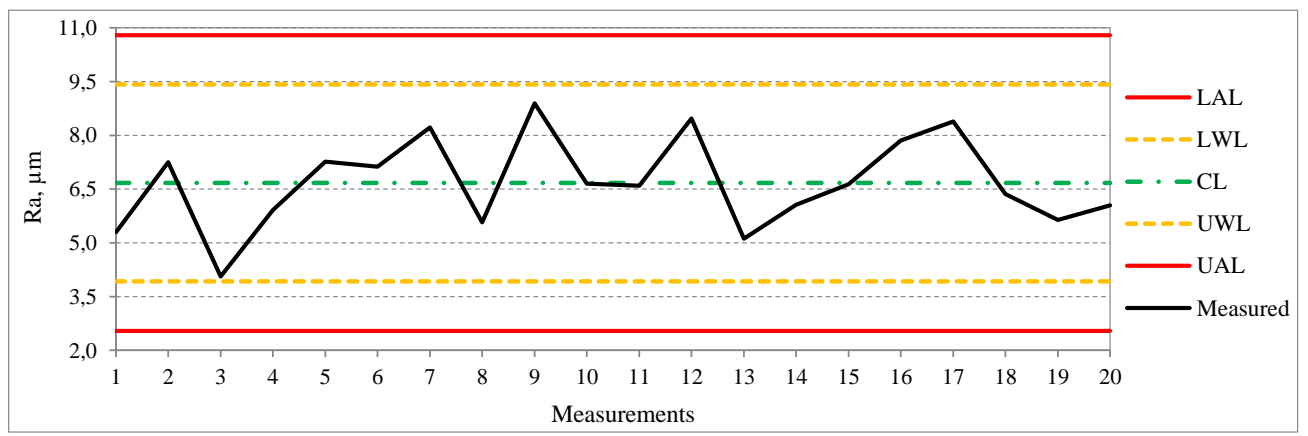

Fig. 13. $i$-chart for laser power of $2000 \mathrm{~W}$ and cutting speed of $4000 \mathrm{~mm} / \mathrm{min}$

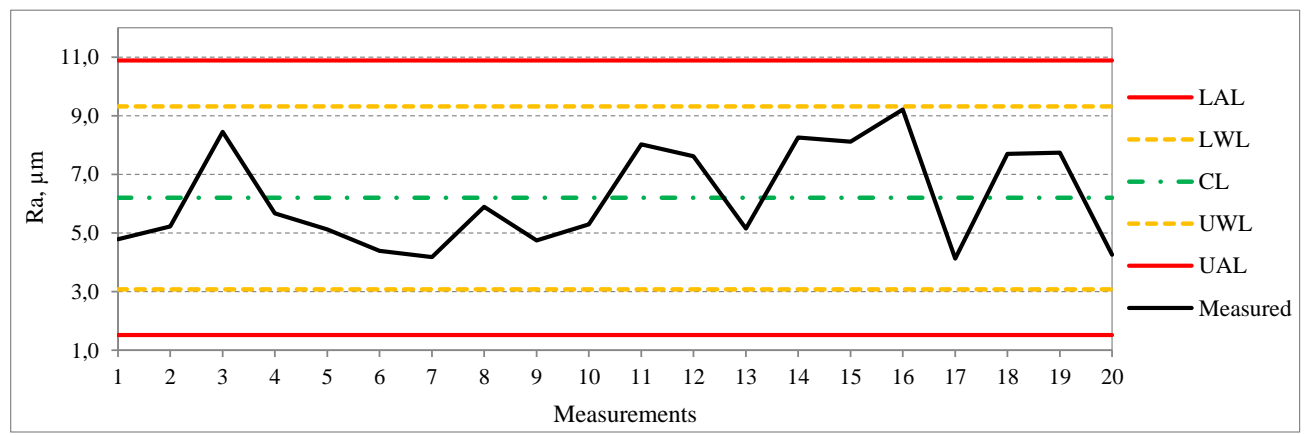

Fig. 14. $i$-chart for laser power of $2000 \mathrm{~W}$ and cutting speed of $4500 \mathrm{~mm} / \mathrm{min}$

The below figure 15 relates to $i$-chart for laser power of $2000 \mathrm{~W}$ and cutting speed of $5000 \mathrm{~mm} / \mathrm{min}$. It can be seen that there are even three consecutive points of the chart above the upper warning line (points 15-17), where two of them are even above the upper action line (points 16 and 17), what means that the process is not under control.

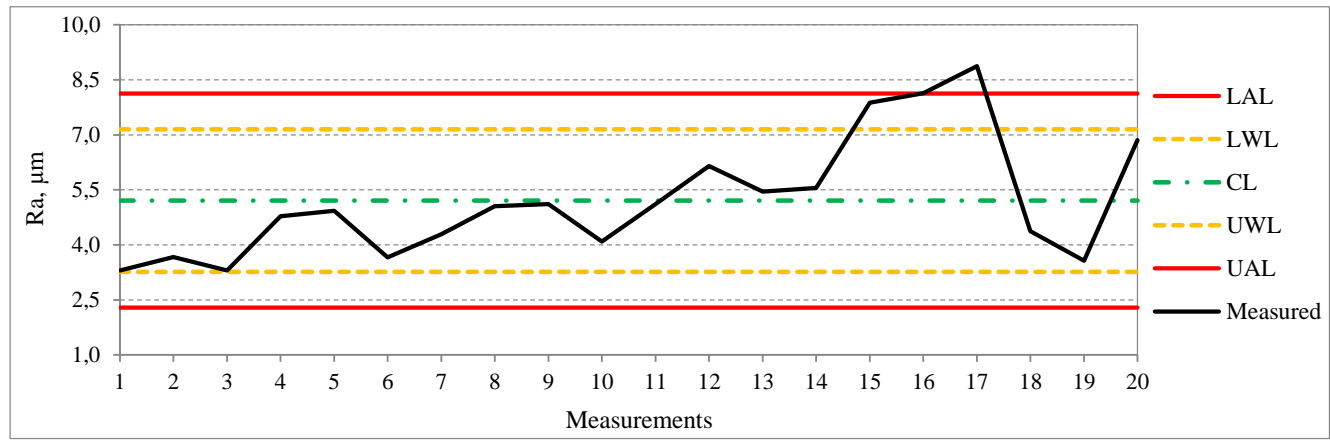

Fig. 15. $i$-chart for laser power of $2000 \mathrm{~W}$ and cutting speed of $5000 \mathrm{~mm} / \mathrm{min}$ 
The below figure 16 relates to $\underline{i}$-chart for laser power of $2000 \mathrm{~W}$ and cutting speed of $5500 \mathrm{~mm} / \mathrm{min}$. It can be seen that there are three points of the chart above the upper warning line (points 12, 13 and 16), what means that the process is not under control.

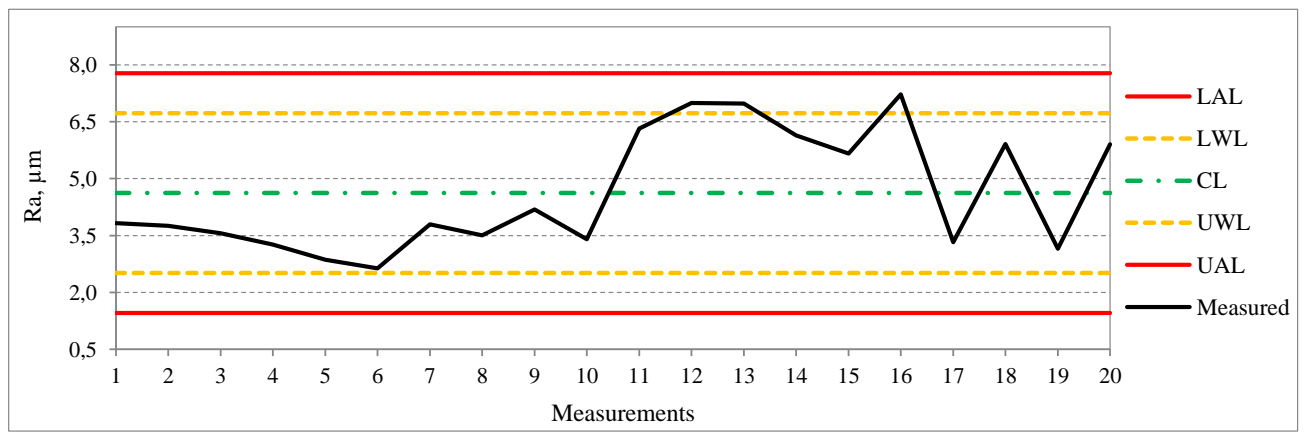

Fig. 16. $i$-chart for laser power of $2000 \mathrm{~W}$ and cutting speed of $5500 \mathrm{~mm} / \mathrm{min}$

The below figure 17 relates to $i$-chart for laser power of $2000 \mathrm{~W}$ and cutting speed of $6000 \mathrm{~mm} / \mathrm{min}$. It can be seen that there is one point of the chart below the lower warning line (point 10), and one point above the upper action line (point 13), what means that the process is not fully under control (since only one of 40 points could be statistically expected).

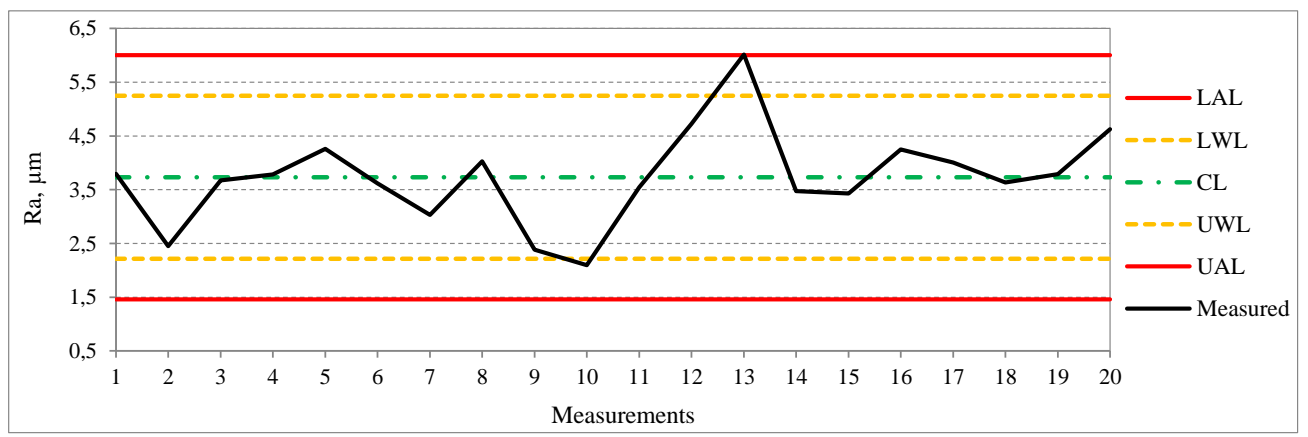

Fig. 17. $i$-chart for laser power of $2000 \mathrm{~W}$ and cutting speed of $6000 \mathrm{~mm} / \mathrm{min}$

To summarize, applying the rules defined with (1) and taking into the account statistically expected number of points outside of defined limits, it can be seen that figures 1-4, representing using laser power of $1500 \mathrm{~W}$ and with increasing cutting speed from $3000 \mathrm{~mm} / \mathrm{min}$ to $4500 \mathrm{~mm} / \mathrm{min}$, show that the process is always in control, since there are no points falling outside the action lines limits (UAL and LAL), or two out of three successive points outside the warning limits (UWL and LWL), or eight points in a run on one side of the mean. Still figure 4 shows two points at the $i$-chart crossing the upper warning line, what is more than expected for only 20 measurements. The $i$-chart for $1500 \mathrm{~W}$ and $3500 \mathrm{~mm} / \mathrm{min}$ also has one point above the upper warning line limit, but it is in line with the statistical expectations.

Regarding the $i$-charts presented at figures 5-10, representing using laser power of $1750 \mathrm{~W}$ and with increasing cutting speed from $3000 \mathrm{~mm} / \mathrm{min}$ to $5500 \mathrm{~mm} / \mathrm{min}$, the first four (up to $4500 \mathrm{~mm} / \mathrm{min}$ ) show that the process is always in control, since there are no points falling outside the action lines limits (UAL and LAL), or two out of three successive points outside the warning limits (UWL and LWL), or eight points in a run on one side of the mean. Of these four only $i$-chart for $1750 \mathrm{~W}$ and $3000 \mathrm{~mm} / \mathrm{min}$ has one point outside of warning limits, what is statistically expected. Figure 9 (1750 W and $5000 \mathrm{~mm} / \mathrm{min}$ ) shows even five points outside of warning limits, 4 above the upper warning line and one below the lower warning line, even three of them above the upper warning line consecutive and thus the process is not in control. The following figure 10 ( $i$-chart for $1750 \mathrm{~W}$ and $5500 \mathrm{~mm} / \mathrm{min}$ ) has only one point above the upper warning line and can be considered as in control.

With the following $i$-charts presented at figures $11-17$, representing using laser power of $2000 \mathrm{~W}$ and with increasing cutting speed from $3000 \mathrm{~mm} / \mathrm{min}$ to $6000 \mathrm{~mm} / \mathrm{min}$, again the first four (up to $4500 \mathrm{~mm} / \mathrm{min}$ ) show that the process is always in control. Of these four only $i$-chart for $2000 \mathrm{~W}$ and $3000 \mathrm{~mm} / \mathrm{min}$ has one point outside of warning limits, what is statistically expected. But the figure $15(2000 \mathrm{~W}$ and $5000 \mathrm{~mm} / \mathrm{min})$ shows even two points outside of upper action limit and one above the upper warning limit, figure $16(2000 \mathrm{~W}$ and $5500 \mathrm{~mm} / \mathrm{min})$ shows three points above the upper warning limit (two of them consecutive), and figure 17 (2000 W and $6000 \mathrm{~mm} / \mathrm{min}$ ) shows one point above the upper action limit and one point below the lower warning limits, thus all three relate to the processes that are not in control. 


\section{Conclusion}

This research was implemented aiming to evaluate the surface roughness of the laser cutting of tungsten alloy, based on different process parameters. Key objective was to find cutting speed and laser power achieving stable process and best cutting quality. In order to find such responses, methodology of statistical process control was used. Developed $i$-charts enable conclusion that increasing the cutting speed leads to potential out of control status for the process, and that the least variable process is achieved with the laser power of $1750 \mathrm{~W}$ and $2000 \mathrm{~W}$, with cutting speed of 3000 $4500 \mathrm{~mm} / \mathrm{min}$. Also, it can be concluded that the process not under control when the laser power of $2000 \mathrm{~W}$ and cutting speed higher than $4500 \mathrm{~mm} / \mathrm{min}$. In order to obtaining uniform surface roughness along the length of the cut in $\mathrm{CO}_{2}$ laser cutting of the examined alloy should be selected cutting speed up to $4500 \mathrm{~mm} / \mathrm{min}$. Future work should include application of this but also other SPC methods for the assessment of "out of control" situations in laser cutting process, including the effect of different process parameters such as type and pressure of assist gas, focus position and other parameters.

\section{References}

[1] D.T. Pham, S.S. Dimov, P.T. Petkov, Laser milling of ceramic components, International Journal of Machine Tools and Manufacture, 47 (2007) 618-626.

[2] P. Schaaf, Laser processing of materials, Springer Series in Materials Science, 139, Springer-Verlag, Berlin, 2010.

[3] P. Di Pietro, Y. Yao, A new technique to characterize and predict laser cut striations, International Journal of Machine Tools and Manufacture, 35 (1995) 993-1002.

[4] R. Adalarasan, M. Santhanakumar, M. Rajmohan, Optimization of laser cutting parameters for Al6061/SiCp/A12O3 composite using grey based response surface methodology (GRSM), Measurement, 73 (2015) 596-606.

[5] K.F. Tamrin, Y. Nukman, I.A. Choudhury, S. Shirley, Multiple-objective optimization in precision laser cutting of different thermoplastics, Optics and Lasers in Engineering, 67 (2015) 57-65.

[6] H.F. El-Labban, E.R.I. Mahmoud, H. Al-Wadai, Laser cladding of Ti-6Al-4V alloy with vanadium carbide particles, Advances in Production Engineering \& Management, 9 (2014) 159-167.

[7] D. Begic, M. Kulenovic, A. Cekic, J. Bliedtner, CW CO2 laser cutting of tungsten alloy using O2 assist gas, Proceedings of the 20th International DAAAM Symposium, Vienna, Austria, 2009, pp. 1345-1347.

[8] J.R. Thompson, J. Koronacki, Statistical Process Control: The Deming Paradigm and Beyond. Chapman \& Hall/CRC, USA, 2002.

[9] D. Bayart, Walter Andrew Shewhart, Statisticians of the Centuries (ed. C. C. Heyde and E. Seneta), New York: Springer, 2001, pp.398-401.

[10] W.H. Woodall, Controversies and Contradictions in Statistical Process Control. Journal of Quality Technology, 32 (2000) 341-350.

[11] J.C. Benneyan, R. C. Lloyd, P.E. Plsek, Statistical process control as a tool for research and healthcare improvement, Qual Saf Health Care, 12 (2003) 458-464.

[12] P. Jalote, A. Saxena, Optimum Control Limits for Employing Statistical Process Control in Software Process, IEEE Transactions on Software Engineering, 28 (2002) 1125-1133.

[13] A. Bakker, P. Kent, J. Derry, R. Noss, C. Hoyles, Statistical Inference at Work: Statistical Process Control as an Example, Statistics Education Research Journal, 7 (2008) 130-145.

[14] B. Vucijak S. Midzic Kurtagaic, A. Ćeric, T. Kupusovic, S. Spago, Assessment of Climate Change Effects to Precipitation Patterns using Statistical Process Control Methods, Annals of DAAAM for 2012 \& Proceedings of the 23rd International DAAAM Symposium, Published by DAAAM International, Vienna, 2012, pp. $0277-0280$.

[15] B. Vucijak, T. Kupusović, S. Midzic-Kurtagic, I. Siladzic, A. Ceric, Evaluation Of The Climate Change Effects to the Precipitation Patterns in the Selected Bosnia and Herzegovina Cities, Thermal Science, 18 (2014) 787-798.

[16] J.S. Oakland, Statistical Process Control, Fifth Edition. Butterworth-Heinemann, An imprint of Elsevier Science, Burlington MA, USA, 2003. 